\title{
Reversible absorption of volatile organic compounds by switchable- hydrophilicity solvents: a case study of toluene with $\mathrm{N}, \mathrm{N}-$ dimethylcyclohexylamine
}

Yingjie Li ${ }^{\mathrm{a}}$, Haiyu Chang ${ }^{\mathrm{a}}$, Hui Yan ${ }^{\mathrm{b}}$, Senlin Tian ${ }^{\mathrm{a}^{*}}$, and Philip G. Jessop ${ }^{\mathrm{c}^{*}}$

${ }^{a}$ Faculty of Environmental Science and Engineering, Kunming University of Science and Technology, Kunming, Yunnan, China 650500

${ }^{b}$ School of Pharmacy, Liaocheng University, Liaocheng 252059, China

'Department of Chemistry, Queen's University, Kingston, K7L 3N6, Canada

* Corresponding author: S. Tian tel./fax: +86-871-65920526; e-mail: tiansenlin@outlook.com P. G. Jessop tel./fax: +1-613-533-6669; e-mail: jessop@queensu.ca

Text S1 Chemicals

Text S2 Theory

Text S3 The effect of water

Figure S1 Apparatus for the absorption experiments

Figure S2 Apparatus for measuring the mass transfer of toluene in $\mathrm{CyNMe}_{2}$

Figure S3 The absorption of toluene in $\mathrm{CyNMe}_{2}$ at various temperatures

Figure S4 Variation of the natural logarithm of the Henry's law constant with the reciprocal of absolute temperature for toluene in different absorbent.

Figure S5 The recovery of $\mathrm{CyNMe}_{2}$ from carbonated water at various temperatures.

Figure S6 Absorption of toluene in $\mathrm{CyNMe}_{2}$ containing various amounts of water.

Table S1 Values of A and B of empirical equation and correlation coefficient

Table S2 Comparison of SHSs and other solvents by $E, \gamma, \eta$ and absorption capacity 


\section{Text S1. Chemicals}

$\mathrm{N}, \mathrm{N}-$ Dimethylcyclohexylamine $\left(\mathrm{CyNMe}_{2}\right)$ and $\mathrm{N}, \mathrm{N}$-dimethylbenzylamine (BDMA) were purchased from Chemical Reagent Co. Ltd.. Washing oil (WO) was obtained from Kunming Iron Co., Ltd. Both benzene and toluene were of analytical grade from Aldrich Chemical Co. $\mathrm{CO}_{2}$ (with purity of $99.999 \%$ ) and $\mathrm{N}_{2}$ (with purity of $99.998 \%$ ) were from GRD Ltd, Kunming. Ultrapure water was obtained from an Agilent purification system. Other chemical reagents were of analytical grade and were used as received without further purification.

\section{Text S2. Theory}

\section{S2.1 Henry's law constants, activity coefficient and viscosity}

Concentrations of toluene in absorbent and the Henry's law constant of toluene were determined by headspace gas chromatography. ${ }^{1,2}$ The liquid phase was analyzed by GC-FID. According to the mass balance, toluene concentration in the liquid phase was calculated by the following equation:

$C_{\mathrm{L}}=C_{\mathrm{S}}-C_{\mathrm{G}}$

Then, the dimensionless Henry's law constant $H, H_{\mathrm{C}}$ and $E$ could be calculated by equations (2)、 (3) and (4), respectively:

$$
\begin{aligned}
& H=C_{\mathrm{G}} / C_{\mathrm{L}} \\
& H_{\mathrm{C}}=H R T \\
& E=P_{\mathrm{G}} / x_{\mathrm{G}}
\end{aligned}
$$

The effect of temperature upon Henry's law constant is great at a constant pressure. At different temperature, two empirical equations were obtained by experiment, and that are the linear relationship between the natural logarithm of the Henry constant and the reciprocal of the absolute equilibrium temperature. The temperature dependence of Henry constant can be described by the Van' t Hoff equation,

$$
\begin{aligned}
& \ln H=-A_{H}+B_{H} / T \\
& \ln E=-A_{E}+B_{E} / T
\end{aligned}
$$

Heymes $^{3}$ gave an equation relating the Henry's law constant $(E)$ to the activity coefficient $(\gamma)$ which was used to calculate the activity coefficient of toluene in different absorbents (equation 7).

$$
\gamma=E / P^{\text {sat }}
$$


Viscosities were obtained from Lange's Handbook of Chemistry ${ }^{4}$ or determined using an NDJ Series Digital Viscometer.

\section{S2.2 Evaluation criteria for absorption performance}

Evaluation criteria for absorption performance of $\mathrm{CyNMe}_{2}$ and other solvents include thermodynamic equilibrium parameters, such as Henry constant $(E)$, activity coefficient $(\gamma)$ and viscosity $(\eta)$ values for the gas-liquid absorption system. Absorbents with lower $E$ (or higher $\gamma$ ) and lower $\eta$ are expected to have superior absorption performance. Because the overall absorption coefficient, $K$, is mainly determined by $E$, while $E$ determines the absorption capacity and thus is related to $\gamma$, lower $E$ or lower $\gamma$ mean higher absorption capacity ${ }^{3}$. The diffusion coefficient $\left(D_{\mathrm{AB}}\right)$ is inversely proportional to the viscosity $(\eta)$ of absorbent according to the relation: $D_{\mathrm{AB}}=\mathrm{f}(1 / \eta) . D_{\mathrm{AB}}$ determines the gas-liquid mass transfer rate, so low $\eta$ means relative high absorption. Because no accurate thermodynamic data were found in the literature for toluene gas-liquid phase equilibrium in selected absorbents, experimental were performed to obtain this data.

\section{S2.3 Mass transfer}

Because adequate mass transfer is crucial to this process, the mass transfer mechanism was studied for the absorption step, including whether the mass transfer resistance is mainly located in the gas or liquid film. This information is of practical significance for scale-up of this method in industry.

Experiments on gas liquid mass transfer of VOC into the SHS were carried out in a doublestirred reactor (Fig. S3), including evaluation of the diffusion of gaseous component from the bulk gas phase, the diffusion through the gas interface to liquid interface, dissolution into liquid absorbent, and liquid phase diffusion. The liquid phase diffusion exhibits the inverse direction relative to gas phase diffusion. For gas-liquid absorbing processes, the resistance of mass transfer is used to describe the mass transfer mechanism (Lu et al., 2008). ${ }^{5}$ The mass transfer coefficients, $K_{\mathrm{L}}$ and $K_{\mathrm{G}}$, can be expressed as shown in Eq. (15) and (20) in the section below.

\section{S2.3.1 $K_{\mathrm{L}}$ calculations}

$K_{\mathrm{L}}$ was determined as described in previous papers. ${ }^{6,7}$ It was assumed that the mixing of the gas and the liquid phases was ideal. Henry's law constant was the main parameter for the 
$K_{\mathrm{L}}$ calculation. In the present work, the VOC absorption is physical absorption and the pressure is low, so the ideal gas law is applicable for the absorption system.

Though the experiment was semi continuous, in order to maintain the volume constant, absorbent was added continuously into reactor in each $10 \mathrm{~min}$, the conservation of mass can be expressed by:

$V_{\mathrm{G}} C_{\mathrm{AG}}^{0}+V_{\mathrm{L}} C_{\mathrm{AL}}^{0}=V_{\mathrm{G}} C_{\mathrm{AG}}^{\mathrm{t}}+V_{\mathrm{L}} C_{\mathrm{AL}}^{\mathrm{t}}$

As no VOC was present in the absorbent at $t=0\left(C_{\mathrm{AL}}^{0}=0\right)$, equation (8) can be rearranged as:

$C_{\mathrm{AL}}^{\mathrm{t}}=\frac{V_{\mathrm{G}}}{V_{\mathrm{L}}}\left(C_{\mathrm{AG}}^{0}-C_{\mathrm{AG}}^{\mathrm{t}}\right)$

The time derivative of the available concentration is

$\frac{\mathrm{d} C_{\mathrm{AL}}^{\mathrm{t}}}{d t}=-\frac{V_{\mathrm{G}}}{V_{\mathrm{L}}} \frac{\mathrm{d} C_{\mathrm{AG}}^{\mathrm{t}}}{d t}$

According to the two-film theory, the VOC absorption rate in the liquid phase is given as follows:

$N_{\mathrm{A}}=\frac{V_{\mathrm{L}}}{A} \frac{\mathrm{d} C_{\mathrm{AL}}^{\mathrm{t}}}{d t}=K_{\mathrm{L}}\left(C_{\mathrm{AL}}^{*}-C_{\mathrm{AL}}^{\mathrm{t}}\right)$

A combination of equation (10) and (11) leads to:

$-\frac{V_{G}}{A} \frac{d C_{\mathrm{AG}}^{\mathrm{t}}}{d t}=K_{\mathrm{L}}\left(C_{\mathrm{AL}}^{*}-C_{\mathrm{AL}}^{\mathrm{t}}\right)$

Using the Henry constant, the $\mathrm{C}_{A L}^{*}$ can be expressed as

$C_{\mathrm{AL}}^{*}=\frac{C_{\mathrm{AG}}^{\infty}}{H}$

At equilibrium, the gas concentration between toluene and absorbent can be expressed as: $C_{\mathrm{AG}}^{\infty}=\frac{H V_{\mathrm{G}}}{V_{\mathrm{L}}+H V_{\mathrm{G}}} C_{\mathrm{AG}}^{0}$

A combination of equation (9) (12) (13) and (14) leads to a linear equation:

$\ln \frac{C_{\mathrm{AG}}^{\mathrm{t}}-C_{\mathrm{AG}}^{\infty}}{C_{\mathrm{AG}}^{0}-C_{\mathrm{AG}}^{\infty}}=-\frac{A}{V_{\mathrm{L}}} K_{\mathrm{L}} t$

By plotting $\ln \frac{C_{\mathrm{AG}}^{\mathrm{t}}-C_{\mathrm{AG}}^{\infty}}{C_{\mathrm{AG}}^{0}-C_{\mathrm{AG}}^{\infty}}$ against $\frac{A}{V_{\mathrm{L}}} t$, a straight line was obtained whose slope gives the mass transfer coefficient $K_{\mathrm{L}}$. 


\section{S2.3.2 $K_{\mathrm{G}}$ calculations}

According to the two-film theory, the VOC absorption rate in the gas phase is given by:

$$
N_{\mathrm{A}}=-\frac{V_{\mathrm{G}}}{A} \frac{d C_{\mathrm{AG}}^{\mathrm{t}}}{d t}=K_{\mathrm{G}}\left(P_{\mathrm{AG}}^{\mathrm{t}}-P_{\mathrm{AG}}^{*}\right)
$$

Because the absorption pressure is low, the ideal gas law is applicable, according to the Amagat law $P_{\mathrm{AG}}^{\mathrm{t}}$ and $P_{\mathrm{AG}}^{*}$ can be expressed by:

$$
\begin{aligned}
& P_{\mathrm{AG}}^{\mathrm{t}}=C_{\mathrm{AG}}^{\mathrm{t}} R T \\
& P_{\mathrm{AG}}^{*}=C_{\mathrm{AG}}^{\infty} R T
\end{aligned}
$$

A combination of equations (16), (17), and (18), leads to a linear equation:

$$
-\frac{V_{\mathrm{G}}}{A} K_{\mathrm{G}} d t=\frac{1}{R T} \frac{\mathrm{d} C_{\mathrm{AG}}^{\mathrm{t}}}{C_{\mathrm{AG}}^{\mathrm{t}}-C_{\mathrm{AG}}^{\infty}}
$$

After integration, this leads to a linear equation:

$$
\ln \frac{C_{\mathrm{AG}}^{\mathrm{t}}-C_{\mathrm{AG}}^{\infty}}{C_{\mathrm{AG}}^{0}-C_{\mathrm{AG}}^{\infty}}=-\frac{A R T}{V_{\mathrm{G}}} K_{\mathrm{G}} t
$$

It should be noted that when $C_{\mathrm{AG}}^{\mathrm{t}}>C_{\mathrm{AG}}^{\infty}$, calculated $K_{\mathrm{L}}$ and $K_{\mathrm{G}}$ value could be reasonable and valid.

\section{Text S3. The effect of water}

\section{S3.1 The effect of water content in $\mathrm{CyNMe}_{2}$}

The solubility (mass $\%$ ) of water in $\mathrm{CyNMe}_{2}$ is $5.0 \%$ (at $\left.30^{\circ} \mathrm{C}\right), 8.0 \%\left(40^{\circ} \mathrm{C}\right), 11.3 \%\left(50^{\circ} \mathrm{C}\right)$, and $13.8 \%\left(60^{\circ} \mathrm{C}\right){ }^{8}$ These mixtures containing different concentrations of water were obtained by addition of $0.849 \mathrm{~mL}$ water into $19 \mathrm{~mL} \mathrm{CyNMe}_{2}(5 \%), 1.358 \mathrm{~mL}$ water into $\mathrm{mL} \mathrm{CyNMe}_{2}(8 \%)$, $1.919 \mathrm{~mL}$ water into $17.74 \mathrm{~mL} \mathrm{CyNMe} 2(11.3 \%)$, and $2.343 \mathrm{~mL}$ water into $17.22 \mathrm{~mL} \mathrm{CyNMe}$ (13.8\%). The absorption processes of different absorption system were performed at 430 $\mathrm{mL} / \mathrm{min} \mathrm{N}_{2}$ carried $27 \mathrm{~g} / \mathrm{m}^{3}$ toluene.

\section{S3.2 The effect of a $\mathrm{CO}_{2}$-containing gas mixture on wet $\mathrm{CyNMe}_{2}$}

A mix of $8.1 \mathrm{wt} \%$ water in $\mathrm{CyNMe}_{2}$ was prepared as representative of the recycled amine that would be received from the separator if the separator were being maintained at $40{ }^{\circ} \mathrm{C}$. The water/amine liquid mixture was maintained at $25{ }^{\circ} \mathrm{C}$ in a constant-temperature water bath. A 
gas mixture of $10 \mathrm{wt} \% \mathrm{CO}_{2}$ in $\mathrm{N}_{2}$ was bubbled through this liquid mixture for $2 \mathrm{~h}$. Within 10 min of the onset of bubbling, the monophasic mixture split into two liquid phases, the lower (aqueous) phase being approximately $1 / 10^{\text {th }}$ the volume of the liquid mixture. A similar experiment but having $7.9 \mathrm{wt} \%$ water, $89.4 \mathrm{wt} \% \mathrm{CyNMe}_{2}$, and $1.3 \mathrm{wt} \%$ toluene gave the same result.

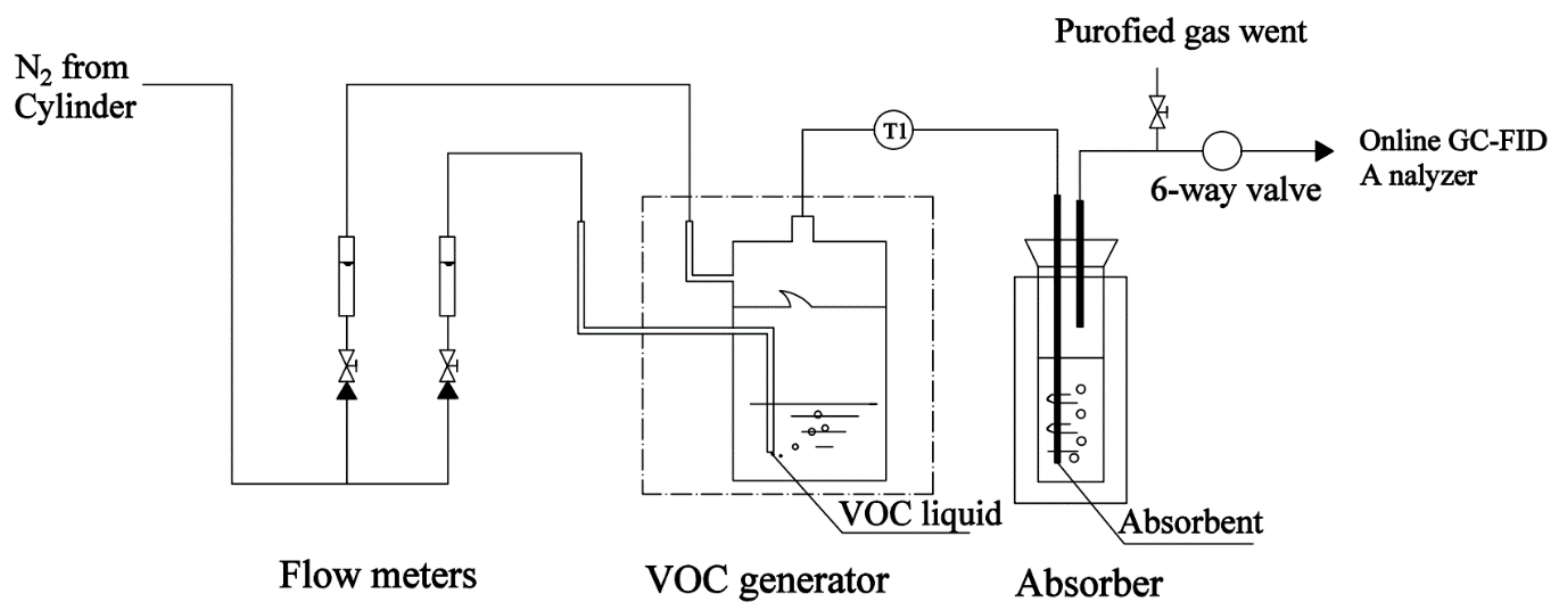

Figure S1. Apparatus for the absorption experiments

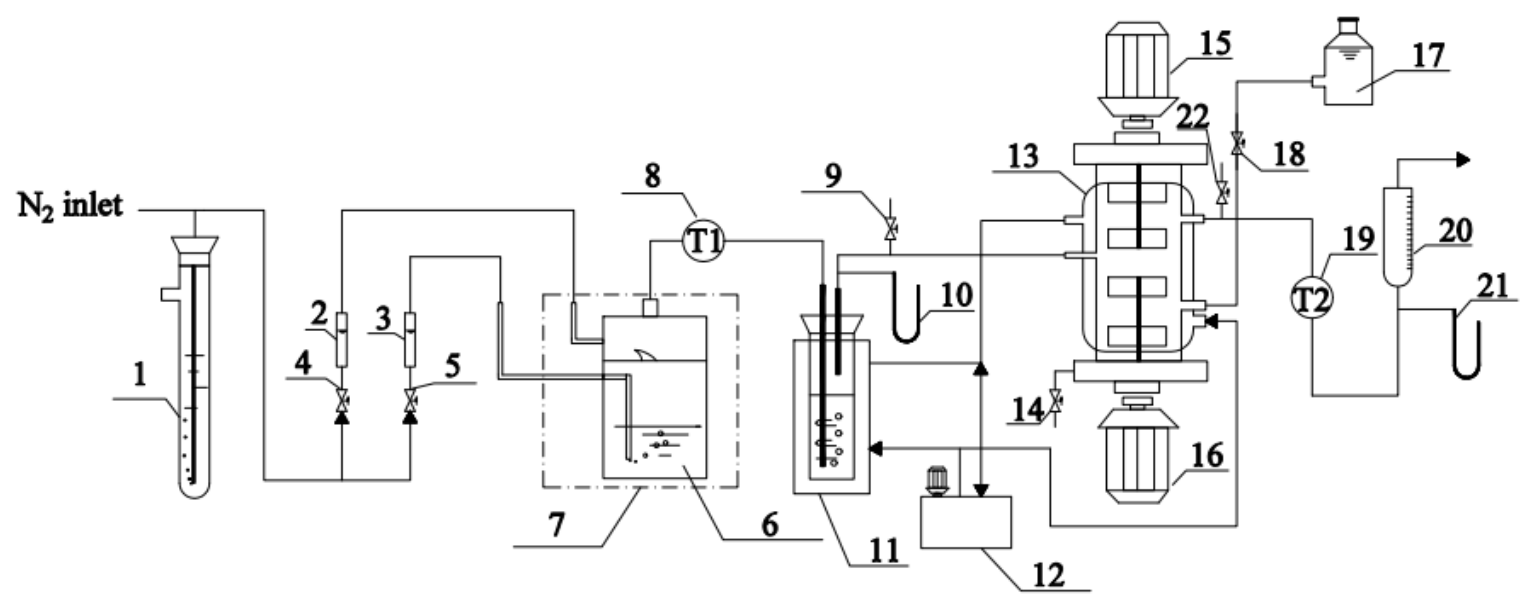

Figure S2. Apparatus for measuring the mass transfer of toluene in $\mathrm{CyNMe}_{2}$. 1. Regulator; 2, 3. Gas flow-meters; 4, 5. Gas control valve; 6. Toluene vapor generator; 7, 12. Water bath; 8. Inlet thermometer; 9. Gas sampling point (inlet); 10. Manometer; 11. Water saturator; 13. Stirred cell reactor; 14. Absorbent sampling point; 15, 16. Driving motors; 17. Absorbent bottle; 18. Absorbent control valve; 19. Exit thermometer; 20. Soap film flow-meter; 21. Manometer; 22. Gas sampling point (outlet). 


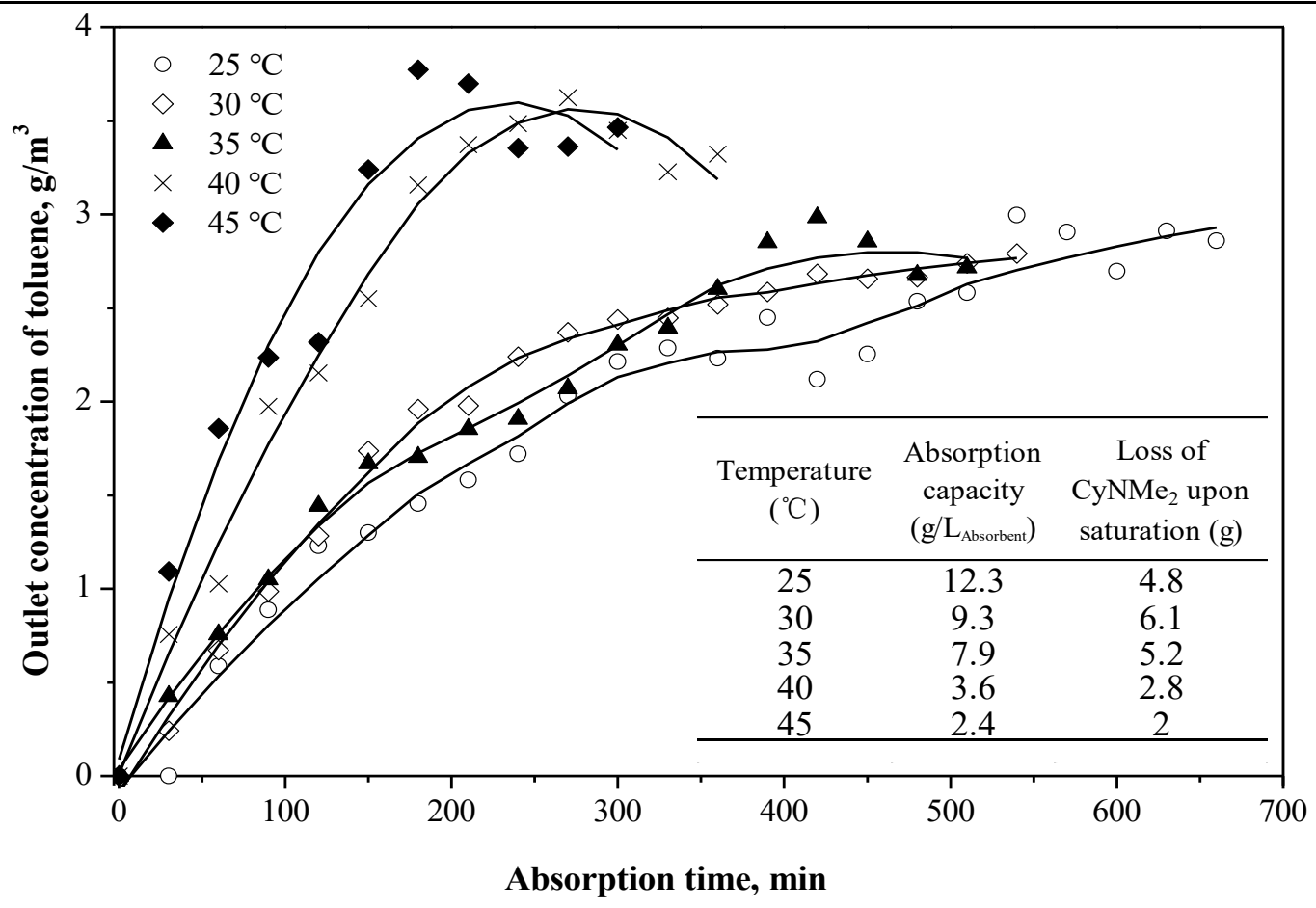

Figure S3. The absorption of toluene in $\mathrm{CyNMe}_{2}$ at various temperatures. $430 \mathrm{~mL} / \mathrm{min} \mathrm{N}_{2}$ carried $2.7 \mathrm{~g} / \mathrm{m}^{3}$ toluene absorbed by $20 \mathrm{~mL}$ of $\mathrm{CyNMe}_{2}$.

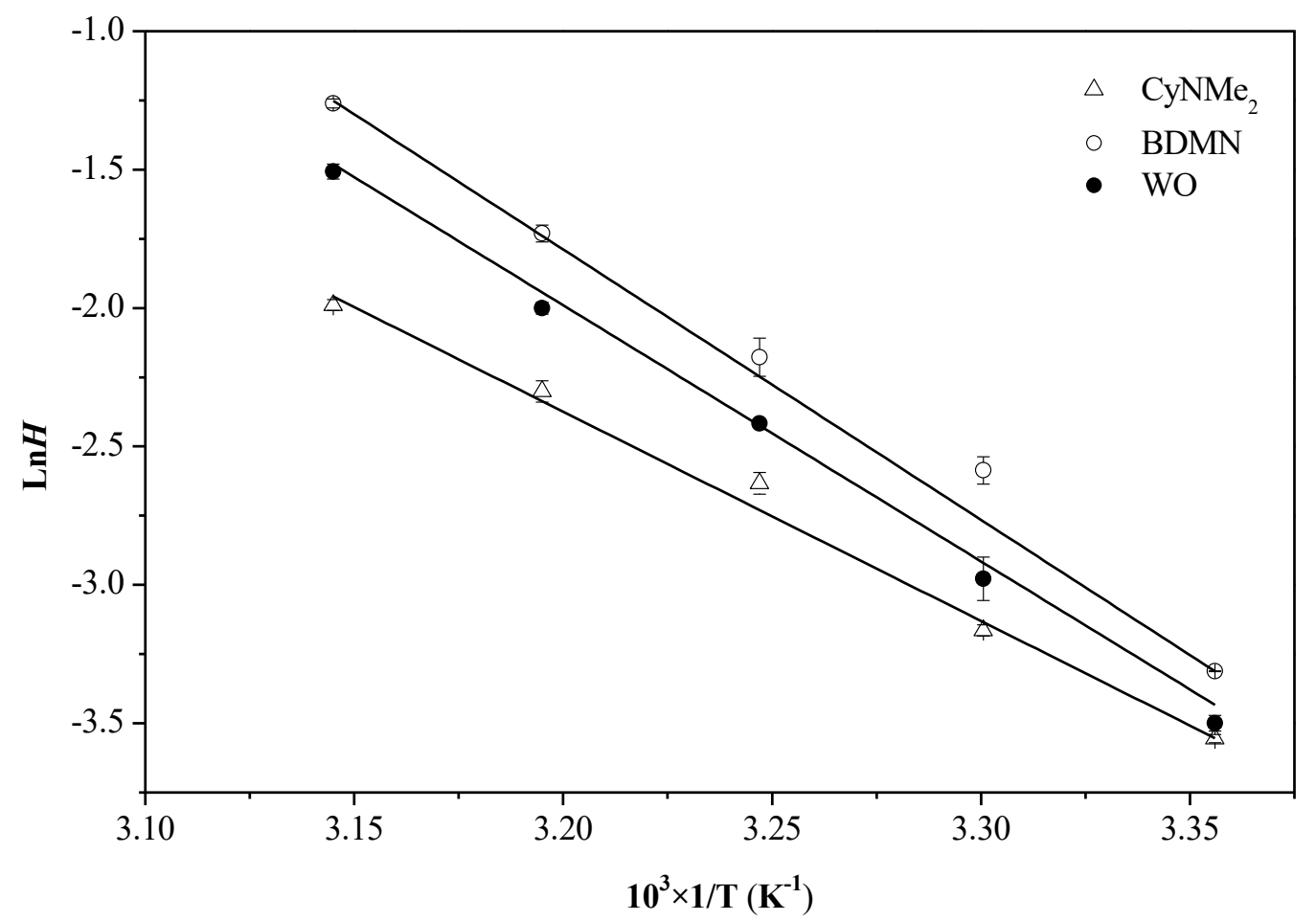

Figure S4. Variation of the natural logarithm of the Henry's law constant with the reciprocal of absolute temperature for toluene in different absorbent. 


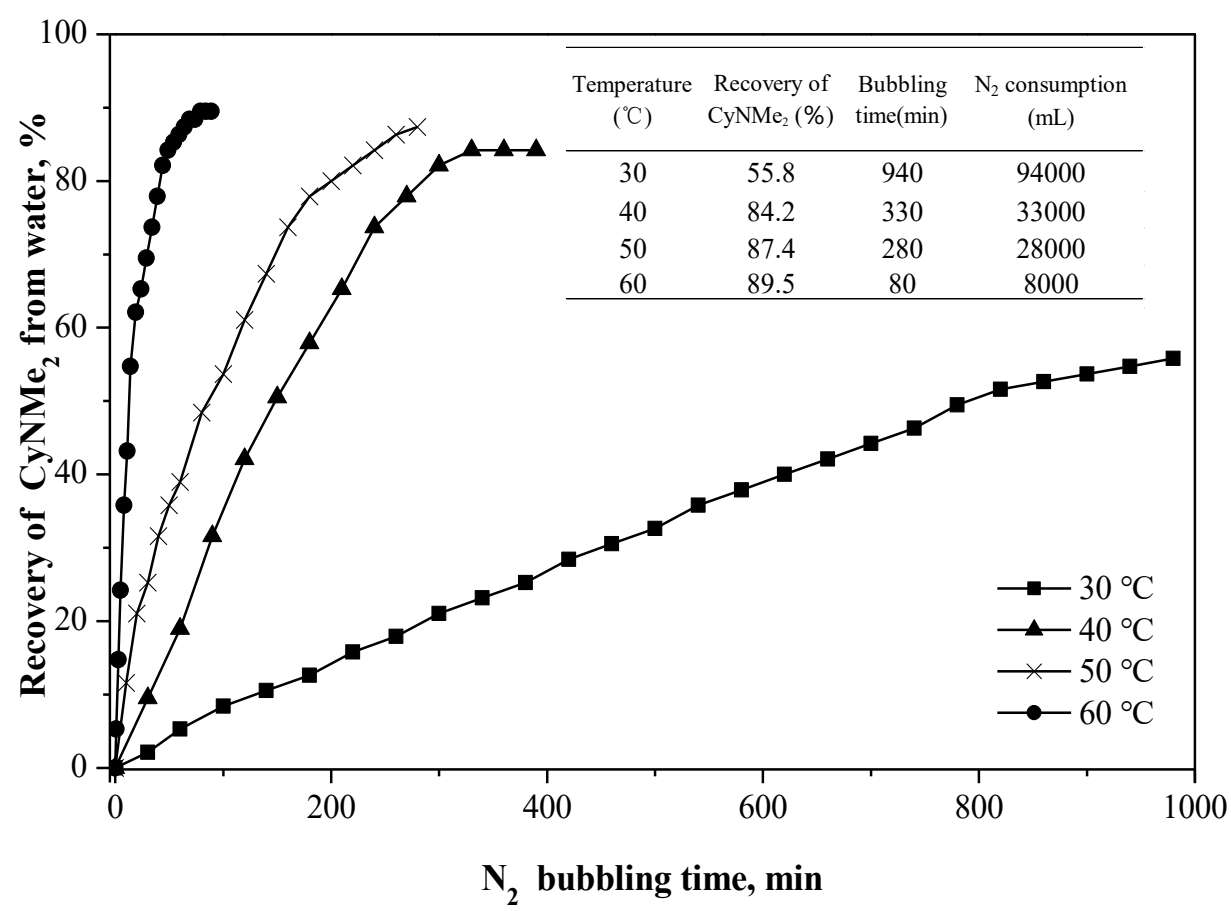

Figure S5. The recovery of $\mathrm{CyNMe}_{2}$ from carbonated water at various temperatures. 100 $\mathrm{mL} / \mathrm{min} \mathrm{N}_{2}$ was bubbled into a single-phase aqueous mixture prepared by mixing $\mathrm{CyNMe}_{2}(10$ $\mathrm{mL})$ and $\mathrm{UP}$ water $(10 \mathrm{~mL})$ and then bubbling $\mathrm{CO}_{2}(30 \mathrm{~mL} / \mathrm{min})$ through the mixture at $25^{\circ} \mathrm{C}$. The volume of $\mathrm{CyNMe}_{2}$ did not reach $100 \%$ because of volatile losses.

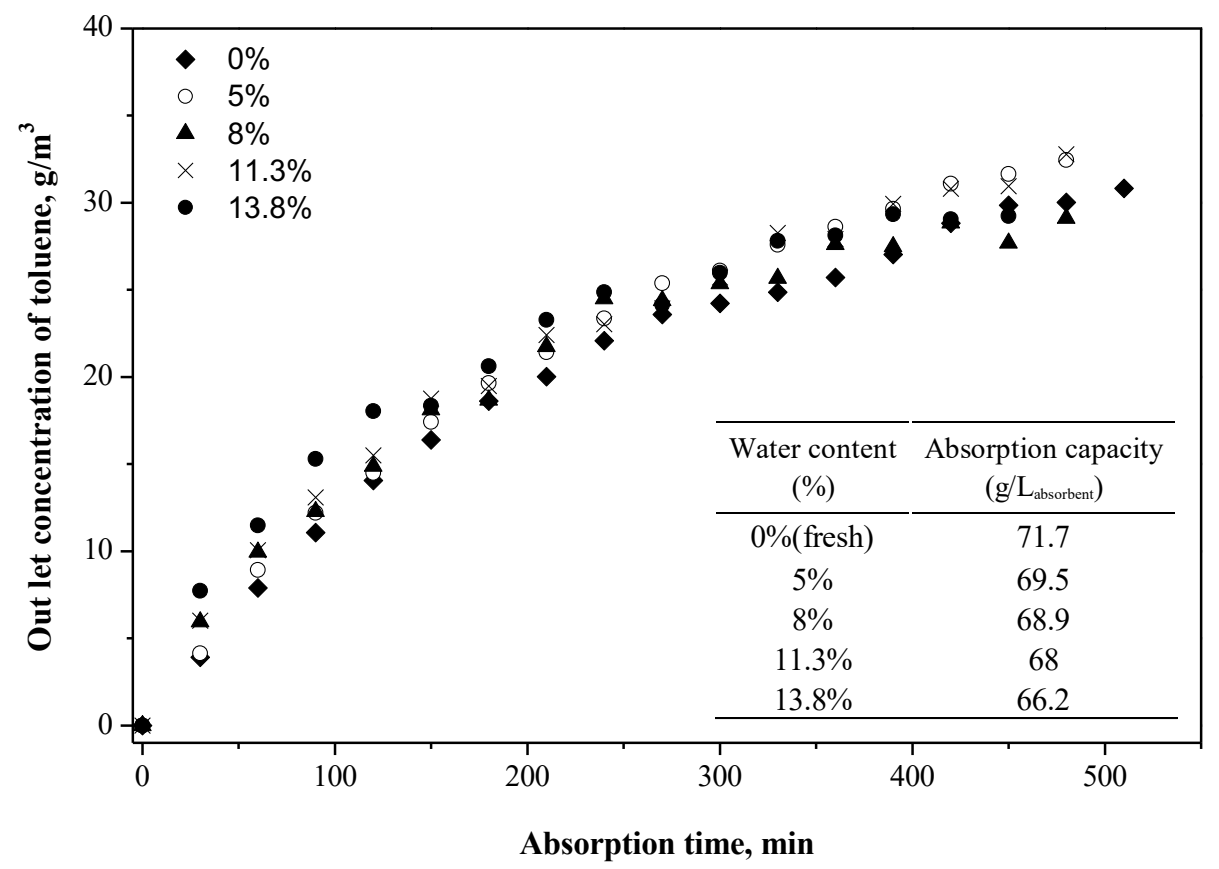

Figure S6. Absorption of toluene in $\mathrm{CyNMe}_{2}$ containing various amounts of water. $430 \mathrm{~mL} / \mathrm{min}$ $\mathrm{N}_{2}$ carried $27 \mathrm{~g} / \mathrm{m}^{3}$ toluene into $20 \mathrm{~mL}$ of $\mathrm{CyNMe}_{2}$ containing various amounts of water. 
Table S1. Thermodynamic parameters for the absorption of toluene by switchablehydrophilicity solvent $\mathrm{CyNMe}_{2}$

\begin{tabular}{ccccc}
\hline$T(\mathrm{~K})$ & $K_{\mathrm{d}}(1 / \mathrm{H}) \times 10^{-3}$ & $\Delta G(\mathrm{~kJ} / \mathrm{mol})$ & $\Delta H(\mathrm{~kJ} / \mathrm{mol})$ & $\Delta S(\mathrm{~J} / \mathrm{mol} / \mathrm{K})$ \\
\hline 298 & 4.72 & -20.85 & & \\
303 & 3.23 & -20.14 & & \\
308 & 1.90 & -19.44 & -63.02 & -141.50 \\
313 & 1.34 & -18.73 & & \\
318 & 0.99 & -18.02 & & \\
\hline
\end{tabular}

Table S2. Values of A and B of empirical equation and correlation coefficient

\begin{tabular}{ccccccc}
\hline \multirow{2}{*}{ Absorbent } & \multicolumn{3}{c}{$\ln H$ and $1 / T$} & \multicolumn{3}{c}{$\ln E$ and $1 / T$} \\
\cline { 2 - 7 } & $A_{\mathrm{H}}$ & $B_{\mathrm{H}}$ & $R_{H}^{2}$ & $A_{\mathrm{E}}$ & $B_{\mathrm{E}}$ & $R_{E}^{2}$ \\
\hline CyNMe $_{2}$ & -17.021 & -7590 & 0.993 & -22.426 & -7736 & 0.986 \\
BDMA & -23.465 & -9414 & 0.989 & -28.356 & -9410 & 0.991 \\
WO & -21.939 & -9012 & 0.997 & -28.085 & -9409 & 0.998 \\
\hline
\end{tabular}


Supplementary Materials

Table S3. Comparison of Henry constant $(E)$, activity coefficient $(\gamma)$, dynamic viscosity $(\eta)$, and absorption capacity of SHSs with other solvents.

\begin{tabular}{|c|c|c|c|c|c|}
\hline Absorbent & $\begin{array}{l}E(\mathrm{~atm}) \\
\left(25^{\circ} \mathrm{C}\right)\end{array}$ & $\begin{array}{c}\gamma \\
\left(25^{\circ} \mathrm{C}\right)\end{array}$ & $\begin{array}{c}\eta(\mathrm{Pa} \cdot \mathrm{s}) \\
\left(20^{\circ} \mathrm{C}\right)\end{array}$ & $\begin{array}{l}\text { Absorption capacity } \\
\qquad(\mathrm{g} / \mathrm{L})\left(25^{\circ} \mathrm{C}\right)\end{array}$ & $\begin{array}{l}\text { Concentrations } \\
\mathrm{C}_{\mathrm{g}, \text { toluene }}\left(\mathrm{g} / \mathrm{m}^{3}\right)\end{array}$ \\
\hline Washing oil (WO) & 0.030 (this study) & 0.78 (this study) & 0.0041 (this study) & 14.6 (this study) & 2.7 (this study) \\
\hline N,N-dimethylbenzylamine (BDMA)(SHS) & 0.036 (this study) & 1.09 (this study) & 0.0013 (this study) & 13.3 (this study) & 2.7(this study) \\
\hline Di(2-ethylhexyl) adipate (DEHA) & $0.02^{3}$ & $0.52^{3}$ & $0.0125^{3}$ & $13.20^{3}$ & $3.7^{3}$ \\
\hline N,N-dimethylcyclohexylamine $\left(\mathrm{CyNMe}_{2}\right)(\mathrm{SHS})$ & 0.029 (this study) & 0.75 (this study) & 0.0011 (this study) & 12.3 (this study) & 2.7(this study) \\
\hline Diisobutyl phthalate (DIBP) & $0.034^{3}$ & $0.88^{3}$ & $0.0378^{3}$ & $10.60^{3}$ & $3.7^{3}$ \\
\hline Diisoheptyl phthalate (DIHP) & $0.028^{3}$ & $0.73^{3}$ & $0.055^{3}$ & $9.06^{3}$ & $3.7^{3}$ \\
\hline Diisodecyl phthalate (DIDP) & $0.025^{3}$ & $0.65^{3}$ & $0.1188^{3}$ & $8.40^{3}$ & $3.7^{3}$ \\
\hline Polyethylene 400 (PEG 400) & $0.040^{3}$ & $1.05^{3}$ & $0.1336^{3}$ & $6.80^{3}$ & $3.7^{3}$ \\
\hline Silicon oil (PDMS) & $0.056^{3}$ & $1.46^{3}$ & $0.0198^{3}$ & $5.31^{3}$ & $3.7^{3}$ \\
\hline Polyethylene glycol 300 (PEG 300) & $0.082^{3}$ & $2.14^{3}$ & $0.0755^{3}$ & $4.22^{3}$ & $3.7^{3}$ \\
\hline
\end{tabular}




\section{Nomenclature}

$A \quad$ cross-sectional area of the double-stirred reactor $\left[\mathrm{m}^{2}\right]$

$A_{\mathrm{H}}, A_{\mathrm{E}}, B_{\mathrm{H}}, B_{\mathrm{E}} \quad$ regression coefficients [-]

$C_{\mathrm{G}} \quad$ concentration in gas phase $\left[\mathrm{g} / \mathrm{m}^{3}\right]$

$C_{\mathrm{L}} \quad$ concentration of $\mathrm{A}$ in bulk liquid $\left[\mathrm{g} / \mathrm{m}^{3}\right]$

$C_{\mathrm{S}} \quad$ concentration of saturated liquid of toluene and absorbent $\left[\mathrm{g} / \mathrm{m}^{3}\right]$

E Henry constant [atm]

$H \quad$ Henry's constant [-]

$H_{\mathrm{C}} \quad$ Henry constant $\left[\mathrm{atm} \cdot \mathrm{m}^{3} / \mathrm{mol}\right]$

$K_{\mathrm{L}} \quad$ liquid-phase mass transfer coefficient [m/s]

$K_{\mathrm{G}} \quad$ gas-phase mass transfer coefficient $\left[\mathrm{mol} /\left(\mathrm{s} \cdot \mathrm{m}^{2} \cdot \mathrm{atm}\right)\right]$

$M_{\mathrm{S}} \quad$ gas molecular weight of toluene $[\mathrm{g} / \mathrm{mol}]$

$N_{\mathrm{A}} \quad$ absorption rate $\left[\mathrm{mol} /\left(\mathrm{m}^{2} \cdot \mathrm{s}\right)\right]$

$P \quad$ total pressure gas phase $[\mathrm{KPa}]$

$P_{\mathrm{G}} \quad$ partial pressure of toluene in the gas phase [KPa]

$P^{\text {sat }} \quad$ saturation pressure of the toluene $[\mathrm{KPa}]$

$Q_{\mathrm{G}} \quad$ gas flow rate $\left[\mathrm{m}^{3} / \mathrm{s}\right]$

$R \quad$ ideal gas constant $=8.314[\mathrm{~J} /(\mathrm{mol} \cdot \mathrm{K})]$

$T \quad$ temperature [K]

$t \quad$ time $[\mathrm{s}]$

$V_{\mathrm{G}} \quad$ volume of the gas phase in reactor [L]

$V_{\mathrm{L}} \quad$ volume of the liquid absorbent [L]

Greek letters

$\gamma \quad$ activity coefficient $[-]$

$\eta \quad$ dynamic viscosity $[\mathrm{Pa} \cdot \mathrm{s}]$

$\rho_{\mathrm{S}} \quad$ density of soluble gases under the actual operating temperature $\left[\mathrm{kg} / \mathrm{m}^{3}\right]$

Superscrip

$0, t, \infty \quad$ time

* equilibrium

\section{Subscripts}

in inlet of the gas stream

out outlet of the gas stream 


\section{References}

1 Y. H. Kim and K. H. Kim, A simple method for the accurate determination of the Henry's law constant for highly sorptive, semivolatile organic compounds. Anal. Bioanal. Chem., 2016, 408, 775-784.

2 K. B. Lodge and D. Danso, The measurement of fugacity and the Henry's law constant for volatile organic compounds containing chromophores. Fluid Phase Equilibria, 2007, 253, 7479.

3 F. Heymes, P. Manno-Demoustier, F. Charbit, J. L. Fanlo and P. Moulin, A new efficient absorption liquid to treat exhaust air loaded with toluene. Chem. Eng. J., 2006, 115, $225-$ 231.

4 J. A. Dean, Lange's Chemistry Handbook, Version 15 th World Book Inc, 1999-10.

5 J. Wang, P. Lu, Z. Wang, C. Yang and Z. S. Mao, Numerical simulation of unsteady mass transfer by the level set method. Chem. Eng. Sci., 2008, 63, 3141-3151.

6 E. Dumont, G. Darracq, A. Couvert, C. Couriol, A. Amrane, D. Thomas, Y. Andrès and P. Le Cloirec, Volumetric mass transfer coefficients characterising VOC absorption in water/silicone oil mixtures. Chem. Eng. J., 2013, 221, 308-314.

7 E. Dumont, Y. Andrès and P. Le Cloirec, Mass transfer coefficients of styrene and oxygen into silicone oil emulsions in a bubble reactor. Chem. Eng. Sci., 2006, 61, 5612-5619.

8 R. M. Stephenson, Mutual solubilities: water + cyclic amines, water + alkanolamines, and water + polyamines. J. Chem. Eng. Data, 1993, 38, 634-637. 